\title{
Patrimônio e performance cultural: experiência e territorialidade na conquista do espaço*
}

Eloísa Pereira Barroso**

Resumo: O presente artigo tem como objetivo fazer um exercício de reflexão teórica sobre os conceitos de território, performance cultural e patrimônio imaterial, com o intuito de procurar ressaltar a correlação entre as ideias de memória, cultura, identidade e territorialidade. Entende-se aqui o conceito de performance numa perspectiva ampla em que o mesmo se refere a um sentido relativo ao acontecimento, ao desejo humano de experienciar, ou seja, à presentificação das ações humanas performadas como uma expressão singular de identidades na territorialização dos espaços por meio dos sentidos atribuídos ao patrimônio cultural pelos grupos sociais. Neste artigo buscamos um percurso teórico-metodológico no qual a proposta é evidenciar, por meio de relações entre as categorias de análise, que os processos de produção da expressão desse patrimônio se realizam não enquanto produto cristalizado, mas como um ato concreto de criação e recriação, de significação e ressignificação das representações dos sujeitos em um campo de disputas de memórias, pois que a ação humana expressa produção de sentidos no aqui e agora que, expressos via performance, territorializam os espaços.

Palavras-chave: Patrimônio. Performance. Identidade. Memória e território.

\footnotetext{
"Este texto é fruto de pesquisa iniciada em 2013, inserida no grupo de pesquisa credenciado ao CNPQ, Laboratório de História e historiografia do Brasil, sob minha liderança.

* Professora na Universidade de Brasília (UnB). Doutora em Sociologia pela Universidade de Brasília (UnB).

E-mail: eloisabarroso@uol.com.br, https://orcid.org/0000-0002-6850-0234
}

Anos 90, Porto Alegre, v. 25, n. 48, p. 151-180, dez. 2018 
Segundo Jean Baudrillard, "[...] a única coisa que nos dá conta do real não são as estruturas coerentes da técnica, mas as modalidades de incidência das práticas sobre as técnicas” (1976, p. 16). À luz dessa observação é possível pensar o território, na medida em que ele nos permite pensar a natureza do espaço a partir do resultado material das ações humanas ao longo do tempo. Ao se conceber o espaço como o lugar no qual se configuram e reconfiguram as práticas sociais, pressupõe-se que esse espaço se transforma e se organiza pela força dos movimentos sociais humanos e, por consequência, a ação humana ali expressa se torna história viva. As funções sociais se realizam nesse espaço em forma de camadas de memórias que mobilizam etapas de um passado, que se constituem em um palimpsesto em que é possível extrair significados da ação da sociedade sobre o espaço, de maneira a se dotar a forma espacial de conteúdo social.

Nessa perspectiva, o estudo do território se configura como um campo no qual incidem diversas possibilidades de abordagem, pois não se pode esquecer que ele é resultado de um passado objetivado de formas sociais, formas essas que configuram modalidades de leitura do mundo social no qual se entranha um presente invasor, com marcas de outrora, um presente que não se realiza plenamente, mas que rememora um tempo olvidado, de maneira a tentar agir sobre a sociedade para qualificá-la e dotá-la de sentido.

O território, enquanto categoria de análise, permite à história inúmeras possibilidades, pois os grupos sociais criam diversas formas de apropriação do espaço em diferentes processos de territorialização. Como nos lembra Milton Santos (2002, p. 330), se o território é o espaço em uso, então o espaço é, ao mesmo tempo, "futuro imediato e passado imediato, um presente ao mesmo tempo concluído e inconcluso, num processo sempre renovado" pelas territorialidades ali impressas. Enfim, a sociedade produz territorialidades diversas, nas quais o espaço é apropriado de acordo com o imaginário social instituído sob diferentes representações.

Nesse sentido, a apropriação do espaço é carregada de subjetividade no processo de territorialização, pois, na medida em que atribuímos sentido ao mundo, nós também nos expressamos sobre ele. As nossas representações incidem sobre os espaços que 
compõem aquilo que nos é dado a conhecer como real. Por meio das representações nos apropriamos dos espaços, transformamos o vivido em significados partilhados por nós mesmos e por outros no processo de territorialização.

Pensar o território implica o esforço em acessar os significados do vivido de maneira a oferecer possibilidades de apropriação do espaço, pois as representações, nesse processo, se associam às sensibilidades postas pelos diferentes atores sociais. Os homens atribuem sentidos ao mundo por meio das representações e, conforme Sandra Pesavento, elas são "[...] matrizes geradoras de condutas e prática sociais dotadas de força integradora e coesiva” (2003, p. 39). As representações pressupõem uma ausência que é presentificada em uma perspectiva de aproximação e distanciamento, em que os homens elaboram ideias sobre o real traduzidas em discursos, símbolos, imagens, rituais, enfim, práticas sociais.

Para Roger Chartier (1990), as representações estão em acordo com o universo experimentado pelo sujeito. Não se deslocam do mundo social, são formas de atribuir sentido ao espaço, são possibilidades de construção de territórios, pois imprimem significados aos espaços em uso. Elas são invariavelmente relacionadas ao espaço, organizam, significam e atribuem sentido à vida das pessoas, demandam uma forma de operar, oferecendo elementos suficientes para a produção de significados ou de sentidos.

As representações sociais revelam os usos e as construções dos espaços pelos indivíduos. Por meio das representações os espaços habitam os indivíduos e os indivíduos habitam o espaço através das experiências vividas e interpretadas nos processos de interação social. O espaço se coloca como o lócus no qual se constroem laços sociais, lugares de memória e identidade nas práticas da vida em sociedade. Nele é possível o reconhecimento da pluralidade cultural dos grupos sociais.

Para Michel de Certeau (1994), essa dinâmica lugar/espaço ocorre nas representações presentes nos relatos de espaço, pois esses relatos "efetuam, portanto um trabalho que, incessantemente, transforma lugares em espaços ou espaços em lugares. Organizam também os jogos das relações mutáveis que uns mantêm com os outros." (CERTEAU, 1994, p. 200; DELEUZE, 1997, p. 203). Para 
o autor, "Todo relato é [...] uma prática do espaço. [...] Tem a ver com as táticas cotidianas, faz parte delas [...]” (1994, p. 200). Se, para Certeau, as práticas cotidianas como falar, ler, circular, fazer compras ou preparar refeições, entre muitas outras, são expressões da cultura de um povo no processo de territorialização por meio de práticas sociais (1994, p. 47), pode-se afirmar então que o processo de territorialização está condicionado às práticas sociais. Nessa ordem de pensamento, o território se realiza como o espaço apropriado no qual se configuram as relações sociais situadas em um tempo histórico.

O processo de territorialização constrói experiências cotidianas, cria nos sujeitos o sentimento de pertencimento que compõe a busca pela singularidade de uma ação expressiva e por um pensamento no qual se partilha um mundo comum às subjetividades vividas, aos dramas individuais e coletivos... É por meio dele que nos construímos no tempo e no espaço como sujeitos de nossas histórias.

Portanto, falar de território é falar de práticas sociais em um espaço e em um tempo. Pierre Bourdieu (2007) percebe essas duas categorias como substratos essenciais para o sujeito experienciar o mundo social; é a partir delas que o sujeito elabora seus fazeres, vivencia suas dores, seus amores, enfim, constrói esquemas de percepção, de pensamento e de ação. De maneiras distintas, ao habitar os espaços, ele estabelece sua forma de existir através de processos de ordenação simbólica, de atribuição de sentidos, ou seja, de práticas sociais.

Para Cecília Londres (2009), as práticas sociais são decorrentes de um processo no qual os sujeitos históricos da produção cultural atribuem sentidos e valores às ações e aos objetos a partir de uma sensibilidade partilhada. As práticas sociais permitem a percepção da experiência humana de maneira a construir um imaginário social no qual se consubstancia o conhecimento sensível apreendido pelos sentidos do indivíduo para que este possa organizar o mundo concreto. As práticas sociais unem experiências comuns e compartilham memórias coletivas, possibilitam ao ser humano partilhar significados pertinentes a um universo comum. Isso faz com que as práticas sociais se tornem referências culturais capazes de imprimir marcas distintivas por sujeitos distintos (LONDRES, 2009). 
É nesse sentido que a apropriação do espaço se apresenta como uma forma significativa de performances culturais. Segundo Sainy Veloso, performances são

[...] os desempenhos coletivos reiterados, de papéis culturais construídos e prescritos por um conjunto de normas sociais cristalizadas, os quais são reencenados em ato presente, de maneira ritualizada ou não... de acordo com um determinado jogo de interesses e poderes" (VELOSO, 2014, p. 196).

As performances culturais como padrões expressivos da vida social se efetivam com base na memória e na vida social cotidiana. No espaço público, as performances ressignificam a memória e instituem representações do ser em uma sociedade através de atuações e expressões que reapresentam o passado performaticamente. No jogo social, a performance estabelece "rotinas", modelos de ação preestabelecidos pelo imaginário social, seja na reafirmação ou na negação do mesmo. Assim, no sentido de equacionar os termos performance, territorialização e patrimônio - pensa-se o conceito de performance referenciado em um sentido relativo ao acontecimento, compreende-se a performance como o ato deliberado de vivenciar e comunicar, no presente, as ações humanas, com toda a carga expressiva e singular de identidades performadas no aqui e agora. Nesse sentido, as ações, em última instância, se constituem como o lócus, por excelência, de materialização do patrimônio cultural imaterial na apropriação do espaço. Assim, a performance, nessa relação com processos de territorialidades e patrimônio cultural imaterial, seria o acontecimento do fato cultural.

O patrimônio cultural imaterial são as práticas, as representações, as expressões, os conhecimentos e as técnicas, bem como os instrumentos, objetos, artefatos e lugares culturais que lhes são associados. Tudo isso só se efetiva enquanto patrimônio quando as comunidades, os grupos e, em alguns casos, os indivíduos os reconhecem como parte integrante do seu modo de vida. O patrimônio cultural imaterial, que se transmite de geração em geração, não é estanque, ele pressupõe processos de criação e recriação constantes pelos grupos sociais. Esse movimento de criar, significar, recriar

Anos 90, Porto Alegre, v. 25, n. 48, p. 151-180, dez. 2018 
e ressignificar ocorre em função do ambiente, das relações com a natureza e de uma história, enfim, em processos de territorialização. $\mathrm{O}$ patrimônio imaterial permite às sociedades a constituição de identidades e pertencimento de modo a contribuir para o reconhecimento e a promoção do respeito à diversidade cultural e à criatividade humana (LONDRES, 2003).

Essa ideia de que fatos culturais intangíveis possuem valor identitário possibilita a inclusão de segmentos sociais e áreas da cultura na formulação da ideia de patrimônio. Dessa maneira, o patrimônio imaterial explicita, valoriza e oficializa a pluralidade e a diversidade cultural dentro de uma sociedade. Falar de patrimônio cultural imaterial é falar para além dos produtos culturais em si (materializáveis), é considerar os agentes - seres humanos concretos - e as condições, formas de produção e reprodução dos bens culturais que abarcam os processos nos quais se produzem os modos de vida, as performances, os saberes, os fazeres e modos de transmiti-los.

Cabe salientar que a definição de patrimônio imaterial não pressupõe o congelamento de uma forma conjuntural específica com possibilidades de arquivamento, pois pensar em patrimônio cultural imaterial é pensar em uma dinâmica na qual estão incrustadas uma variedade de formas e significados. Por isso, quando se estuda o patrimônio imaterial há que se ter em foco os processos de produção, e não os produtos culturais propriamente; nessa ordem de pensamento, compreender os atos de performar pode auxiliar nos estudos sobre os patrimônios intangíveis. Pois é no aqui e agora específico do ato concreto de criação e recriação, expressão e comunicação, que essa variedade de significados, dada por esses bens, se constitui em performances, ações fugazes referenciadas em matrizes e sistemas simbólicos definidos que são, no ato de performar, produzidos, reproduzidos ou questionados.

Assim, as danças, rituais, canções e outros tipos de performances que necessitam dos corpos humanos estão sempre inseridos em uma dinâmica social, espacial e temporal, nas quais seus significados só podem emergir a partir do contexto no qual as ações acontecem. As performances são sempre produzidas a partir de processos de (re) contextualização. Portanto, cabe indagar quando falamos de 
patrimônio e performance: por que as pessoas performatizam? $\mathrm{O}$ quê elas querem comunicar com suas performances?

A performance como essa possibilidade de "materialização" do intangível cria uma série de deslocamentos espaciais e temporais, na medida em que esse presente imediato da performance, a memória corporal dos sujeitos que performam associada aos possíveis significados pretendidos nessa interação entre os que performam e os espectadores, acaba por conceber as práticas sociais enquanto processo e não como produtos relativos ao patrimônio cultural. Dessa maneira, a construção de significados possíveis, dada pelo ato de performar, permite uma historicidade na qual comunidades participam da elaboração de seus bens culturais, da territorialização dos seus espaços, na medida em que elas "recriam” e são criadoras dos significados pertinentes à tradução de sua cultura.

Para Richard Schechner (2003), uma das funções da performance seria o reforço da identidade social das comunidades ou grupos sociais. Nesse sentido, é mister a compreensão dos conceitos de performatividade e de materialização performática quando falamos de performances culturais como possibilidades de manifestações dos corpos na constituição do patrimônio intangível ou imaterial de uma determinada cultura local, pois os sujeitos envolvidos com os patrimônios culturais os envolvem em suas performances de maneira a atribuir-lhes significados.

Segundo Rubens Silva, a performatividade "[...] desloca a ênfase na identidade como descrição, como aquilo que é [...] para a ideia de 'tornar-se', para uma concepção da identidade como movimento e transformação" (1996, p. 92). A performatividade, para além da descrição do porquê das ações expressivas humanas acontecerem de uma determinada maneira e não de outra, faz emergir as representações e proposições que possibilitam o acontecimento das performances. Ou seja, a performatividade permite vermos as práticas, os lugares de troca cultural e de transmissão de conhecimento e valores.

São as performatividades que nos permitem olhar as formas como as comunidades se expressam através de estruturas de comportamento codificado, em que as memórias individual e social se instituem a partir de um senso de compartilhamento de lembranças e de atividades que fazem da performance uma tradição visível na 
esfera pública, ou seja, celebração de datas comemorativas, aniversários, batizados, casamentos etc., ilustram como as sociedades representam a história. Essa associação entre performance e patrimônio cultural imaterial permite às comunidades manifestarem um sentido de si reconhecível, ainda que sempre em transformação. Assim, as performances realizadas pelos grupos sociais podem ser lidas como "[...] estratégias identitárias de um grupo social”, nos termos de Joël Candau (2016). Essas estratégias identitárias do grupo envolvem um jogo complexo muito mais amplo do que a exibição passiva de um conjunto de hábitos incorporados. As identidades são construídas a partir de relações, reações e interações sociais viabilizadas por sujeitos sociais que performam o patrimônio cultural. Esse ato de performar permite constituições de identidades nas quais estão impressas visões de mundo e sentimentos de pertencimento. Assim, cada performance envolve o estabelecimento ou reafirmação de uma visão de mundo, de performatividades. Estas confabulariam, por conseguinte, as elocuções que informariam o significado que cada performance cultural procura preservar e fazer permanecer no tempo os significados atribuídos pelo sujeito às suas tradições, ao seu patrimônio cultural.

As tradições culturais, entendidas como invenções transmitidas e reinventadas, nos termos de Hobsbawn e Ranger (1994), faz com que nos ritos e ordenações permaneçam certas práticas ou modos de perceber o mundo como conhecimentos, práticas e valores que são transmitidos de geração em geração. Dessa forma,

"Na tradição, o nexo de continuidade entre o passado e o presente, existe um aspecto permanente e outro suscetível à mudança. A tradição resulta de um processo de decantação cultural e da hibridação que deriva do passado transformado e de sua incorporação ao presente” (ARÉVOLO, 2004, p. 928).

Se as tradições são o legado que uma geração transmite para outra e que confere elementos identitários aos grupos, haja vista ser a identidade uma construção social, então é possível afirmar que elas são conformadas através de preceitos e performances que se desenrolam sustentadas por idiossincrasias entre preceitos individuais, 
mas que estão em íntima relação com as construções simbólicas de uma cultura. É pertinente salientar que essa cultura está circunscrita socialmente, em processos dinâmicos, nos quais se verificam permanências, transformações e resistências.

Cabe lembrar que os atos performativos expressam o repertório do patrimônio cultural imaterial, e eles só podem ser transmitidos de uma geração para outra por meio dos corpos. Embora sejam práticas vivas, eles contêm uma resistência que se contrapõe a noções de efemeridade, na medida em que reiteram alguns comportamentos ao transmitirem informação, memória cultural e identidade coletiva de uma geração ou grupo para outra. Esse conhecimento criado, armazenado e comunicado por meio de práticas incorporadas de indivíduos de geração em geração, não se limita ao corpo individual, na medida em que ele pode ser transferido. Mas cabe salientar que mesmo que os gestos sofram alterações quando performatizados, os grupos sociais os performatizam novamente. Ajoelhar para rezar, por exemplo, poderia ser entendido para além de uma prática individual. Nesse sentido, o ato de performar que acontece aqui e agora, algo fugaz, intangível e irreproduzível, que só existe em ações humanas, nos permite perceber que os indivíduos performam fatos culturais. Esse entendimento nos possibilita verificar os processos sociais enquanto algo dinâmico, que rejeita a ideia de patrimônio enquanto indicativa de algo autêntico, calcado em uma imobilidade, plantado em algum lugar do passado, capaz de se transformar em tradição no tempo e no espaço. Por isso, nega-se a ideia de um patrimônio imaterial reificado e revestido de autoridade para servir de modelo e referência a ser reproduzido sempre de uma mesma maneira, de forma a estetizar o passado, pois há que se considerar que a dimensão imaterial da cultura é inapreensível, a não ser quando ela é performada na fugacidade do acontecimento.

Para a teoria da performance, falar em autenticidade é falar do momento no qual cada performance é realizada, é salientar as condições sociais, econômicas e históricas, é apreender a intencionalidade de cada ato performado. Dessa maneira, o autêntico, sob o ponto de vista da performance, está relacionado à materialização de atos performáticos em determinado momento. Assim, o seu registro, seja ele sonoro, visual etc., não é o fato cultural em si, 
mas uma reprodução técnica que se constitui como referência para outras performances culturais, também únicas, mesmo que filiadas a uma mesma tradição.

O foco não é, portanto, estabelecer uma estetização do passado para se tentar definir o que é mais tradicional ou mais antigo. $\mathrm{O}$ importante é reconhecer que a materialização do fato cultural por meio de uma performance implica em processos sensoriais e emocionais para os grupos sociais. Isso porque a tradição permite ao sujeito o desejo de experimentar, no seu corpo, a sua sensibilidade no aqui e agora, o ato concreto de (re) criação, expressão e comunicação referenciadas em sistemas simbólicos definidos no ato de performar, em que ao mesmo tempo reproduzem ou questionam significados instituídos (LONDRES, 2003).

John Dawsey (2007) questiona essa noção de autenticidade ligada a um passado cristalizado quando estabelece analogias entre a teoria da performance de Turner (1987) e as reflexões de Walter Benjamim (1987) sobre as grandes tradições narrativas. Para Dawsey, esses dois autores, ao construírem em suas análises uma arqueologia da experiência humana na modernidade, apresentam um desmoronamento da tradição e o empobrecimento da experiência. A experiência, segundo Benjamin, está inscrita numa temporalidade comum a várias gerações (GAGNEBIN, 1999, p. 57). Ela provém de gerações anteriores da comunidade e se atualiza na repetição da história pelo narrador, a fim de se perpetuar na memória do ouvinte (que, por sua vez, deverá atualizá-la para as próximas gerações). Qualquer indício de "singularidade" que apareça no "produto final" não é mais que uma fatalidade promovida pelo encontro do corpo e da vida do narrador com a experiência a ser transmitida.

Para Benjamin, esse ato de transmissão da experiência não se constitui porque o sujeito tenha consciência da experiência. Por isso os efeitos da transmissão dessa experiência não podem ser lidos como uma simples repetição da história, mas também como um processo de "distensão do espírito" que se realiza nos atos de performar, criando e recriando significados. Nessa relação entre o sujeito que performa e o que assiste, existe a transmissão da experiência. Isso ocorre porque quando a atenção se volta para a performance, aquele que ouve e assiste "esquece de si mesmo", 
e nesse processo circunscreve-se a possibilidade de se transmitir uma experiência - e mais, a performance se realiza de maneira a transmitir a própria capacidade de transmitir. Para Benjamin, essa transmissão da experiência nada tem de consciente; ao contrário, o autor afirma que a transmissão só se efetiva quanto menos atento à história está o ouvinte. $\mathrm{O}$ narrador benjaminiano não elabora suas histórias pautado por intencionalidade ou vivências individuais, mas a história que performa e atualiza é parte de uma cadeia na qual estão presentes as incontáveis vozes das gerações passadas que se interconectarão com infinitas gerações futuras. Assim, a experiência será transmitida não pelo performador de histórias em si, mas através da própria história, embora valha salientar que haverá sempre uma relação de interdependência do sujeito para a rememoração da performatividade da história. Dessa forma, a performance, como expressão do patrimônio cultural imaterial, se insere num terreno fértil fronteiriço entre a arte e a magia, na medida em que ela é uma forma de arte viva, como bem definem os seus estudiosos na contemporaneidade.

Em síntese, o fato cultural nominado patrimônio imaterial deve ser entendido enquanto sistema de práticas tradicionais reconhecidas e transmitidas de geração em geração ao longo de um tempo e de um espaço. $\mathrm{O}$ patrimônio cultural imaterial caracteriza identidades coletivas, nas quais a autenticidade performada pelos sujeitos a ele circunscrito não se deve a uma origem somente conjetural de maneira localizada. Ele, quando performado, se torna uma recriação singular que contempla o aqui e o agora vivido pelo sujeito que expressa, em cada performance, possibilidades de performatividades que significam as práticas sociais.

Se as práticas sociais, conforme Bourdieu (2003), se referem a um processo interativo no qual o sujeito, o objeto e o grupo social não podem ser considerados isoladamente, então é no jogo dessas interações, dessas relações sociais, que as práticas se consolidam, adquirem significados e são (re) significadas, impregnadas por valores e afetos; elas contribuem para a construção, transformação e instituição do imaginário de determinado grupo social. As práticas sociais são concebidas a partir de uma percepção na qual os sujeitos elaboram o cotidiano por meio de uma ação dinâmica dos grupos 
sociais que os permite intervirem sobre o espaço e construírem referências de lugar para imprimirem suas experiências performadas pelos grupos sociais que definem seu patrimônio cultural. Dessa maneira, o patrimônio é concebido como experiência vivida e partilhada por sujeitos que, a partir de suas práticas sociais, significam o espaço e forjam a sua territorialização por meio da produção social via patrimônio cultural. Hans Gumbrecht nos informa que:

Queremos conhecer os mundos que existem antes que tivéssemos nascido, e ter deles uma experiência direta. Esta experiência direta do passado deveria incluir a possibilidade de tocar, cheirar, provar estes mundos através dos objetos que os constituíram. O conceito enfatiza um longamente subestimado (e mesmo reprimido) aspecto sensual da experiência histórica - sem construir necessariamente uma problemática 'estetização do passado' (GUMBRECHT, 1999, p. 467).

Desta feita, o patrimônio cultural entendido como prática social, através da performance, se configura como forma de apropriação do espaço, na medida em que imprime possibilidade de construção de sentido desse espaço.

O patrimônio, quando performado por sujeitos, torna possível a junção do espaço e de um tempo, onde as práticas sociais se configuram como um processo de valorização e manutenção de bens, de valores coletivos e individuais. Dessa maneira, cria-se uma "consciência patrimonial" em que sujeito e patrimônio se tornam, ao mesmo tempo, parte dos processos de territorialização.

Ao analisarmos práticas e lugares de trocas culturais como lócus de transmissão de conhecimentos e de valores, é possível olharmos as formas como as comunidades se expressam nas estruturas comportamentais, de maneira codificada, através de uma linguagem simbólica na qual se inscrevem a memória social e individual. Essas memórias derivam de um senso de compartilhamento de atividades e lembranças que se fazem visíveis no patrimônio cultural. As representações sociais são o que dão significado às vivências sociais inseridas no tempo e no espaço. Assim, o patrimônio pode ser entendido a partir das representações sociais no processo de 
atribuição de sentidos ao espaço, haja vista ser a partir da perspectiva coletiva que os fenômenos humanos são conhecidos e explicados, sem ignorar o indivíduo nas suas experiências.

Pensar no patrimônio não é só pensar sobre a realidade dada, mas pensar as relações que estruturam e significam essa realidade. O patrimônio é uma construção social, se configura como um elo entre os indivíduos e, nessa perspectiva, não possui um caráter estático, ele é amplo e dinâmico, e só adquire inteligibilidade em um processo circunscrito aos usos que se faz dele no mundo social. Exterior à cultura, o patrimônio se configura como os suportes físicos, as formas particulares e tangíveis de expressão dos padrões culturais. Ele incide sobre os suportes, manifestações e condições concretas de existência do homem. No mundo social, o patrimônio é produzido por uma coletividade, sua existência está em acordo à dinâmica social, sendo que cada grupo, de acordo com os interesses postos no âmbito de suas atividades econômicas, sociais, políticas e culturais, dimensiona as relações sociais de modo a performar identidades culturais e territorialidades na apropriação do espaço.

$\mathrm{O}$ patrimônio cultural possibilita um movimento no qual se cria um mundo onde circulam práticas sociais que advêm do imaginário calcado nas manifestações culturais. Segundo Castoriadis,

[...] o imaginário não é imagem de. É criação incessante e essencialmente indeterminada (social-histórica e psíquica) de figuras/formas/imagens, a partir das quais somente é possível falar-se de 'alguma coisa'. Aquilo que denominamos 'realidade' e 'racionalidade' são seus produtos (CASTORIADIS, 1982, p. 13).

$\mathrm{Na}$ leitura proposta pelo filósofo, o imaginário cria o mundo na medida em que permite ao pensamento conferir sentido a esse mundo. Assim, o real, o ser e a racionalidade se configuram como produtos do imaginário. A instituição imaginária da sociedade estabelece as significações, determina o que tem sentido e o que não tem. A significação que as sociedades dão ao que elas são constrói e evidencia a reflexão que ela faz de si mesma. Pois que a criação do mundo para o homem se coloca como criação de um mundo 
de significações imaginárias sociais, é por meio dessas criações que a humanidade outorga sentido ao mundo.

Dessa forma, o patrimônio cultural permite ao território se consubstanciar como o lócus da experiência. Uma experiência que se coloca em forma de história, de tradição, de memória, de identidade, possíveis de serem performadas. O imaginário social, como um dos mecanismos que regulam a vida coletiva, define, através das referências simbólicas, divisões internas, hierarquizações e instituições sociais, ele exerce um controle da vida coletiva de maneira a se tornar ao mesmo tempo lugar e objeto dos conflitos. É no tempo e no espaço que o território como depositário da experiência guarda acontecimentos, história e memória através de sua capacidade imaginativa ou poiética criada pelo imaginário social expressos no patrimônio cultural, posto que o imaginário se constitui a partir de uma rede simbólica que estrutura os modos de percepção dos indivíduos.

Se a experiência, na concepção de Benjamin (1987), se traduz como a capacidade dos indivíduos de se inserirem em uma tradição compartilhada, pode-se afirmar que esses indivíduos criam códigos e símbolos para acessar os fragmentos do passado no presente via memória. São as reminiscências, os rastros, os fragmentos que possibilitam a experiência ser reabilitada pelo passado no presente. Dessa maneira, o patrimônio seria esses rastros, as ruínas de um passado, ele pode ser concebido como um mediador cultural entre os grupos, haja vista construir referenciais nos quais estão representados os valores e os significados importantes à produção social. Os muitos debates políticos sobre a representação das minorias nacionais, étnicas, sexuais, raciais etc., configuraram uma demanda por memória ampla, permitindo formar um "direito à memória". Esse cenário de reivindicação do direito à memória, nos termos de Paul Ricoeur (2007), talvez seja o que tenha acompanhado a expansão da importância do patrimônio cultural, que, além do aspecto memorial, revela um princípio material, simbólico e funcional de rememoração e preservação, criação e recriação que envolve tanto as manifestações culturais (celebrações, fazeres, saberes...) como os artefatos materiais. 
A memória desperta vestígios de vivências e sensibilidades, ela possibilita a constituição de um sentimento de pertença naqueles que vivenciam o espaço social. A memória permite aos indivíduos produzir identidades diversas com subjetividades que escapam ao enquadramento em sistemas sociais homogeneizantes e pré-definidos a priori pelo pesquisador.

Se a memória é concebida como a atividade de lembrar, então a lembrança, na perspectiva benjaminiana, é acessada pelas necessidades do presente. A memória nos ajuda a repensar nossas suposições enraizadas sobre o presente e sobre o passado. As narrativas suscitadas pela memória proporcionam uma releitura crítica do passado histórico, elas são capazes de questionar as representações dominantes, colocam em cheque os determinismos históricos. Acessar o patrimônio é também acessar, por meio da memória, como os indivíduos atribuem sentidos, símbolos, imagens, significados ao mundo social.

Para Michel Pollak (1989), a memória é construída e definida individual e coletivamente a partir das necessidades colocadas pelo presente. Esse processo de construção da memória possibilita aos sujeitos conhecer temporalidades outras. As memórias individual e coletiva conferem significados ao passado e ao presente de maneira a significar o tempo e o espaço social. Entendida por Pollak (1989) como um fenômeno construído, a memória não está isenta de conflitos, ela se constrói em um espaço dialético entre o que deve ser lembrado e o que deve ser esquecido, se vincula às relações de poder em disputa em um determinado campo. Se são as demandas do presente que legitimam imaginários sociais e constroem as representações, pode-se afirmar ser a memória seletiva, na qual há um caráter de escolha do que deve ser lembrado e o que deve ser excluído.

Nesse ponto, podemos falar mais amplamente de lutas por representações do passado. Lutas por poder, para legitimar conhecimento, atreladas às lutas da memória coletiva. Segundo Elizabeth Jelin, essas "[...] lutas implicam, por parte de diversos atores, estratégias para oficializar ou institucionalizar uma narrativa do passado, alcançar posições de autoridade, ou alcançar quem as ocupam, aceitem e as façam próprias da narrativa que se intenta difundir" 
(2002, p. 30). Também implica uma estratégia para ganhar adeptos, ampliar o círculo que aceita e legitima uma narrativa tanto quanto comportamentos e pactos sociais.

Nesse sentido, o patrimônio como forma de construirmos e selecionarmos determinadas representações, determinadas práticas sociais, legitima processos de rememoração e esquecimentos calcados em um imaginário que insere territorialidades e performa identidades. Conforme Chartier (1990), as representações são entendidas como possibilidades de classificações e divisões nas quais a percepção e apreensão do mundo social se colocam como categorias de percepção do real. Elas não são fixas, mas elaboradas conforme as disposições dos grupos ou classes sociais e, embora busquem a universalidade, são determinadas por interesses dos grupos que as elaboram. As representações não são discursos neutros, estão eivadas de poder e dominação, os quais procuram impor uma autoridade e legitimar escolhas. Nessa relação, tanto a memória quanto o esquecimento se situam em um espaço e tempo instáveis e repletos de pluralidades em que, materializados no patrimônio, configuram a experiência do homem individualmente e coletivamente em uma sociedade.

Segundo Ricoeur (2007), essa operação entre memória e esquecimento não se dá horizontalmente apenas com o exercício da memória nos processos de rememoração. A polissemia de sentidos do que seja o esquecer e o lembrar, ou até mesmo o que se define como memória, não nos possibilita correlações automáticas entre lembrar e esquecer, pois o esquecimento não pode ser lido como uma falha apenas contingencial das funções cerebrais às quais se sujeitam as lembranças. Ele está sujeito à compreensão e à definição das "condições históricas" que norteiam as conjunções e disjunções de produção de narrativas via memória. Isto é, o que se lembra e o que se esquece estão relacionados à maneira como a memória é tratada em determinadas circunstâncias sociais, culturais, ou seja, o que se lembra e o que se esquece tem íntima relação com a forma com que a história é pensada e exercida. Assim, o esquecimento nos atos de performar o patrimônio poderia ser compreendido tanto como resultado quanto como reação ao exacerbado "dever de memória" nos processos de salvaguarda à expansão dos corpos como "lugares de memória" (NORA, 1993)1, em que os processos 
de registros das sociedades se colocam em regimes do presentismo que salientam as controvérsias de um mundo que propaga uma era da testemunha, com o intuito de manter congelados rituais e tradições como formas de "arquivar". A performance, nessa relação entre esquecimento e memória, seria a resposta incômoda à realização da "recordação total" do patrimônio imaterial. Para Ricoeur (2007), a fundamentação das condições do lembrar e do esquecer passa pelo entendimento do tempo e do espaço, enfim, do modo como os sujeitos compreendem a si como históricos em acordo com as identidades assumidas por eles diante do passado e do futuro.

Pollak (1989) concebe a identidade como a "imagem de si, para si e para os outros", ou seja, o indivíduo constrói a imagem de si em relação ao espaço e ao tempo nos quais está inserido, e é nesse espaço e tempo que ele compartilha essa imagem com outros sujeitos. Segundo o autor, essas identidades se constroem em íntima relação com as memórias, que se organizam pelas representações, sejam elas discursivas, imagéticas, textos, normas, leis, dentre outras, e conferem legitimidade para as práticas sociais de maneira a permitir a compreensão das temporalidades vividas no processo de sedimentação das sociedades. Segundo Stuart Hall (2006), a forma como o indivíduo se identifica e percebe a si mesmo acontece a partir da relação construída com o outro, tanto pelas diferenças quanto pelas semelhanças em processos de alteridade.

Dessa maneira, a memória, a partir das demandas do presente, seleciona fragmentos de um passado com o intuito de representar uma realidade, possibilita ao sujeito definir maneiras de pertencimentos sociais, que geram práticas sociais e instituem identidades. Nesse processo de seleção, construção e desconstrução, se estabelece a negociação entre o indivíduo e a sociedade, na qual memória e identidade se consubstanciam nas performatividades em que os arquivos, museus, acervos em geral, monumentos e bens imateriais tornam-se instrumentos que permitem articular a possibilidade de pertencimento coletivo. De certa forma, tais perspectivas, afirmadas por Hall, situam sua análise dentro de uma abordagem situacional da identidade, na qual esta é construída a partir de relações, reações e interações sociais das quais emergem visões de mundo e sentimentos de pertencimento. Nesse panorama, "[...] a identidade 
torna-se uma 'celebração móvel' formada e transformada continuamente em relação às formas pelas quais somos representados ou interpelados nos sistemas culturais que nos rodeiam. É definida historicamente, e não biologicamente" (HALL, 2006, p. 13). Hall e Candau (2016) assinalam que a identidade deve ser pensada sob o signo da provisoriedade, pois, por ser um processo, não permite delimitações ou essencialismos, está sempre em fase de construção.

De certo modo, pensar essa relação entre memória e identidade a partir do patrimônio permite ancoragens de pertencimentos em diversos níveis sociais, haja vista os grupos sociais desejarem que ele funcione como um direito cultural, como um dos aspectos que compõe a sua cidadania, pois, segundo Candau, "[...] a memória, ao mesmo tempo em que nos modela, é, por nós, modelada" (2016, p. 20). Isso expõe a dialética da memória e da identidade que se conjugam, se nutrem mutuamente, se apoiam uma na outra para produzir uma narrativa, uma história, um patrimônio. O próprio patrimônio, ao ser concebido como um processo contínuo de sistematização e distribuição de conhecimento, permite aos sujeitos e grupos sociais mediarem as relações entre si, elaborarem identidades e noções de pertencimento através dos bens culturais. Enfim, o patrimônio oscila entre significações plurais, ora concomitantes e frequentemente conflitantes, ele tem se tornado cada vez mais uma arena de disputas semânticas.

Segundo Candau (2016), o sujeito da rememoração seleciona o que deve estar contido na reconstrução do passado, escolhe algumas lembranças e exclui outras. É nesse instante que começa a domesticação do passado, pois os indivíduos dão forma as suas representações sobre o passado em função das demandas do presente. Nessa escolha, as imagens mnemônicas são mediadas pela linguagem para adquirir sentido, de maneira a moldar a identidade, que por isso se enraíza na memória. Os atos de memória mostram-se como uma aventura pessoal e coletiva em descobrir-se a si mesmo graças a processos de retrospecção. Assim, rememorar torna-se um trabalho empreendido para revisitar e ressignificar o passado, que está calcado no presente como uma forma de significar o agora. Nessa perspectiva, a performance pode ser percebida como um trabalho de reler e ler novamente o patrimônio conferindo a ele 
outros sentidos. Esse é o ponto crucial da relação entre memória e identidade, território e patrimônio, o qual ganha forma por meio da performance, pois, para conferir significado ao tempo vivido e à bagagem de experiências do sujeito, é preciso dar forma a esse tempo por meio de processos de territorialização.

Essa abordagem do patrimônio a partir de uma função memorial com vistas à construção de uma cidadania cultural direciona a significação do passado e do tempo e o fenômeno cultural do patrimônio, que são definidos pelos múltiplos usos e valores atribuídos pelos sujeitos que nele coexistem. $\mathrm{O}$ patrimônio acaba por transpor o ritual memorial de um grupo social; enquanto categoria de análise, o patrimônio imaterial abarca os inúmeros usos da cultura pelos grupos sociais ao realçar os aspectos mnemônicos para construção de cidadania cultural. Porém, é preciso salientar que o patrimônio cultural não é uma arena harmônica, mas um lugar de disputas semânticas que envolvem e transcendem suas funções de rememoração.

Diante do exposto, a memória possui vínculos com a ideia de tradição na medida em que ela se associa à presença do passado. Ela se retroalimenta pelas lembranças ressignificadas em um território por grupos sociais, ela presentifica práticas sociais de um passado nos ritos e ordenações, os quais permitem as percepções do conhecimento nos valores cognitivos e estéticos em que os objetos do passado tornam tangíveis práticas e valores transmitidos de geração em geração, oralmente ou pelo hábito. A tradição como uma construção social introjetada na cultura confere elementos identitários aos grupos, pois são os traços culturais que se movem por entre grupos, permitem que os saberes circulem entre as classes sociais, fazendo com que haja reelaborações contínuas do passado, permitindo ao tecido social a aquisição de novos sentidos. Portanto, os valores culturais que significam o patrimônio configuram e reconfiguram o território pelo viés da memória. Cabe salientar que, junto ao aspecto memorial do patrimônio, outros valores foram consolidados, tal como o direito à cidadania, pois que o direito à memória se torna um exercício dos princípios de direitos sociais pelas comunidades. 
Se o patrimônio é uma fonte de testemunhos, documentos, vivências, e permite ao sujeito experienciar o território por meio de performatividades, pode-se afirmar ser o patrimônio uma possibilidade de representar o movimento para a rememoração coletiva, via performance, o que vai além do fundamentalmente estético e mercantil para uma rememoração no âmbito do particular, haja vista o patrimônio retratar símbolos coletivos. Cabe ressaltar que, embora o bem patrimonial não seja dotado de um valor intrínseco homogêneo, não se pode negar que nele subjazam aspectos mnemônicos e não mnemônicos que estão em múltiplas relações que disputam o mesmo bem cultural em processos de territorialização. $\mathrm{Na}$ apropriação do espaço, os valores não mnemônicos são de ordem variada e correspondem à pragmática do uso e à significação social atribuídas pelas sociedades nos atos de performar aos bens patrimoniais. Isso porque os muitos objetos e as muitas práticas são definidos como patrimônio cultural pelo seu uso cotidiano, tais como o uso religioso, o uso político, o uso comercial, o uso turístico, de um monumento ou de saberes e fazeres. Tais valores correspondem às múltiplas aplicações que um bem cultural é capaz de gerar para um grupo social no que tange ao estabelecimento de uma relação de pertencimento comunitário, o que constitui a base da epistemologia patrimonial. Enfim, os bens patrimoniais de uma sociedade, além de seu aspecto memorial no estabelecimento de uma narrativa nacional, precisam possuir valores voltados ao exercício da vida em comunidade cotidiana. Claro que essas relações conflitantes e ambíguas do patrimônio acabam por gerar narrativas sobre o passado para poderem articular relações sociais no presente; ora essas relações apresentam consonâncias, ora dissonâncias naquilo que deve ou não ser definido como patrimônio cultural.

Nessa perspectiva, o patrimônio cultural se constitui como representação simbólica das identidades de grupos humanos (CRUCES, 1998) em processos de disputas de memórias. A memória mantém uma íntima relação com o passado, portanto dialoga com a história, e esse diálogo nos permite compreender como o homem cria hábitos, como se instituem os costumes, como se transmitem as tradições, como se significa os espaços, enfim, como institui seus patrimônios.

Anos 90, Porto Alegre, v. 25, n. 48, p. 151-180, dez. 2018 
O patrimônio se configura como os rastros deixados pelo passado, nele se inscrevem as lembranças de uma presença que por ora não existe mais. Assim, a memória se utiliza dos rastros para dar significados ao patrimônio, esses significados se instituem nessa tensão entre a presença e a ausência, o patrimônio é a presença do passado que no presente se lembra do passado desaparecido, mas é também presença de um passado que irrompe em um presente. A grandeza das lembranças é a expressão de conteúdos em que se permite analogias das semelhanças e, porque não, das diferenças entre passado e presente. Assim, o que encontramos no patrimônio cultural quando performado pelos sujeitos não é o passado em si, mas a presença do passado no presente. Um passado que retorna, que de alguma forma não passou, reatualizando e recriando o presente.

Pode-se perceber o patrimônio cultural como uma espécie de esforço da sociedade em buscar no passado possíveis entendimentos do presente. Esse processo de reconhecimento confere valor ao âmbito das relações sociais e simbólicas. Pode-se observar que há um esforço contínuo da sociedade em instituir patrimônios como expressão de suas identidades. Se o patrimônio é tudo aquilo que possui valor simbólico para uma comunidade, manifesto em suas práticas sociais, pode-se afirmar que o patrimônio de um grupo social não se distancia da sua história e da sua cultura.

Nessa perspectiva, o patrimônio cultural, seja ele material ou imaterial, é sempre a expressão de valores coletivos representados em suas manifestações, sejam elas de pedra e cal, sejam elas em forma de saberes e fazeres... Portanto, falar de patrimônio cultural não é empreendimento fácil, haja vista ele ser fruto de relações sociais definidas no tempo e historicamente situadas em um campo de significados constituídos espacialmente e temporalmente por disputas de memórias urdidas nas reminiscências discursivas dos sujeitos e das instituições.

Assim, a relação entre patrimônio, território, performance e memória torna-se mais do que uma percepção coletiva e individual, pela consciência ou pela própria ideologia, ela representa uma conjunção na qual as práticas sociais são o que conduz à concretude da relação sujeito-patrimônio, pois a memória é uma construção humana, que se enraíza nas experiências vividas pelo sujeito.

Anos 90, Porto Alegre, v. 25, n. 48, p. 151-180, dez. 2018 
A performance pode mudar significativamente o sentido do patrimônio, mesmo quando ela conserva o sentido da tradição, afinal não se pode esquecer que a memória se conecta a espaços que estão sujeitos a mudanças de sentido. A performance acrescenta uma camada histórica ao palimpsesto patrimonial na medida em que ela permite a constante renovação dos sentidos e significados da cultura, subverte as estratégias de como se pensar sobre os comportamentos e práticas, a performance, enfim, redimensiona a perspectiva de estandardização do patrimônio cultural cristalizado. Nessa perspectiva, o patrimônio cultural mostra as tensões dos processos de territorialização por meio de práticas ritualizadas nas representações sociais dadas por atos performáticos.

Essas configurações de leitura do patrimônio a partir das representações atribuídas pelos sujeitos nos atos de performance se relacionam ao processo de produção das práticas sociais como fator determinante para a constituição de um bem significado como patrimônio cultural. Pressupõe ainda uma articulação complexa entre memória, identidade e representação, na qual se estabelece uma prática de pesquisa interpretativa configurada historicamente como um processo de reconfiguração contínua de experiências da vida dos indivíduos, da realidade social, enfim, de representações situadas em um tempo histórico e elaboradas em um contexto social a partir do cotidiano, do individual e do coletivo.

Analisar o patrimônio cultural significa estabelecer possibilidades de leitura do território através de práticas que privilegiem a apropriação do espaço. No campo da história, a pesquisa, ao abordar a relação entre patrimônio, performance e territorialização, se faz significativa em sua interdisciplinaridade; ao fazer referência aos conceitos postos nos diferentes campos do conhecimento, interpreta as interações possíveis entre eles, calcadas em um aporte teórico na perspectiva de convergir para a História em sua forma narrativa de contar sobre o passado, analisar o presente e projetar um horizonte de expectativa, em temporalidades distintas, na sincronia do tempo histórico. O passado e a história, materializados nos patrimônios, evidenciam normas sociais herdadas do passado e da tradição, de maneira que nos permitem pensar as práticas culturais como atuações, como ações sociais.

Anos 90, Porto Alegre, v. 25, n. 48, p. 151-180, dez. 2018 
O patrimônio cultural, se entendido como uma categoria discursiva de expressão do conhecimento e de práticas culturais, permite ao indivíduo estabelecer um novo modo de se relacionar com o território. O território se constrói a partir de processos sociais, históricos, portanto pode ser lido como elemento do patrimônio que permite a existência de territorialidades múltiplas, e dinamiza a categoria de patrimônio cultural indo além de um patrimônio único, mas para patrimônios diversos.

Esse desejo por uma experiência direta do passado no presente poderia ser atendido com a representação da história pelo patrimônio cultural, pois ele é o passado presentificado, de maneira que sua materialidade permite a recriação de sua presença e, com ela, de seu aspecto sensual. O patrimônio se coloca para além de uma re(a)presentação do passado, no sentido de criar para ele uma materialidade de pedra e cal ou ritualística para além de uma aura de excepcionalidade ou sacralização em processos de espetacularização, ou seja, quando ele re-a-presenta o passado ele o faz existir novamente como presença que articula uma pluralidade de signos, significantes e significados.

Nessa perspectiva, o enfrentamento da problemática dessa relação deve ser concretizado pelo reconhecimento da natureza dinâmica e processual na interação entre patrimônio e território, tempo passado, tempo presente, pois que a complexidade do patrimônio se efetiva como a complexidade dos seus processos que almejam encontros performáticos de experiências singulares que se refazem sempre no presente. A territorialização do espaço via patrimônio não é uma opção segura, mas uma tarefa complexa, dinâmica e abrangente, pois as incertezas nos processos de apropriação do espaço é a única certeza para se experienciar o espaço pela via da sensibilidade e dos sentidos performados historicamente pelos sujeitos da produção cultural, nos bens culturais produzidos dentro das relações de poder instituídas no mundo social.

À compreensão da complexidade dos processos de territorialização via patrimônio impõe-se a reflexão sobre os discursos históricos no que tange às questões que envolvem a territorialização a partir do patrimônio cultural, na medida em que é necessário enfatizar a dinâmica das práticas sociais que comportam subjetividades e

Anos 90, Porto Alegre, v. 25, n. 48, p. 151-180, dez. 2018 
identidades dos mais diversos grupos sociais. Ao se lançar um olhar sobre o espaço e o tempo, é preciso estar atento à transformação no processo de historicização para a compreensão dos mesmos. Pensar o patrimônio cultural é pensá-lo por meio da diversidade que se coloca no processo de territorialização, é pensar na constituição das tradições e da memória como possibilidades que retroalimentam a configuração do espaço marcada por historicidade pertinente à dinâmica das práticas sociais e por memórias em disputa. Isso implica em um processo de interpretação da cultura como produção material e simbólica, que no caso da relação entre patrimônio cultural e território se referem à identidade, à ação, à performance e à memória dos diferentes sujeitos formadores da sociedade. Há que se lembrar que por ser relacional, esse processo envolve tanto aspectos sociais como materiais.

Segundo Rogério Haesbaert, o sentido relacional do território se efetua porque ele "[...] significa simplesmente enraizamento, limite/fronteira. Justamente por ser relacional, o território inclui também o movimento, a conexão, a fluidez" (HAESBAERT, 2006, p. 55), e é nesse movimento que ele se liga à performance enquanto produtora de sentido. Dessa maneira, "[...] todo território é, ao mesmo tempo e obrigatoriamente, em diferentes combinações, funcional e simbólico, pois exercemos domínio sobre o espaço tanto para realizar "funções" quanto para produzir "significados" (HAESBAERT, 2004, p. 55).

O território é um espaço carregado de referências simbólicas em que os símbolos criados constroem o sentido de pertencimento, propiciam a criação de identidades dos indivíduos e favorecem a integração social dos sujeitos ao território. Esses símbolos são responsáveis por criarem uma ordem social com o intuito de estabelecer um processo de integração moral entre os indivíduos que atuam sobre o espaço, de maneira a transformar e imprimir suas perspectivas no território. Há uma profusão de formas simbólicas criadas pelos sujeitos em que se estabelecem formas de ocupação no território. Dessa maneira, são atribuídos uma série de elementos simbólicos que "marcam" a identificação do sujeito com o território.

Se considerarmos que o patrimônio cultural carrega consigo vestígios das relações vividas e imaginadas em um espaço dado, ele 
traz consigo uma ideia de lugar, de modo de vida, ele se orienta em relação à dinâmica cultural posta no sistema de representações inserido no imaginário social, o que transforma o território em memória, em lugar de identidade, em referência histórica, por fim, em um lugar socialmente construído pelos sujeitos nos atos de performarem os fatos culturais.

$\mathrm{Na}$ medida em que o território se coloca como fator histórico, ele adquire uma dupla significação, pois se torna ao mesmo tempo produto e produtor de relações sociais. $\mathrm{O}$ ato de produzir é igualmente o ato de produzir territorialidades, ou seja, o território passa a ser compreendido como um conjunto de formas, formas essas que testemunham uma história escrita tanto no presente quanto no passado. Tais formas podem ser compreendidas como o patrimônio cultural expresso tanto na sua materialidade como na sua significação, que no decorrer da história é imbuído de valores e conteúdos que se ressignificam no conjunto das representações assentadas no imaginário social.

\section{Considerações finais}

O patrimônio como o direito à memória e à história significa no espaço territorial a conquista da cidadania, em que a territorialização desse espaço se constitui como mais um elemento da subjetividade, ou seja, a sociedade não só produz, historicamente, formas espaciais, condições de sobrevivência, mas também reproduz, no seu imaginário, via performance, as representações simbólicas sobre o espaço. Sendo assim, memória, patrimônio, território e performance são conceitos que dialogam com o movimento, com o sentido de exercício de práticas culturais que se fazem presentes nas disputas e lutas políticas que constroem a história do sujeito.

A questão está para além de uma atuação simbólica que corresponda à apropriação ou não do espaço via patrimônio; ao se inserir a relação entre patrimônio e performance na instituição das territorialidades na modernidade fragmentada, o que se propõe é olhar para trás para se entender o presente, constrói-se uma mudança de perspectiva do olhar historiográfico para se buscar 
outra coerência, como propôs Sandra Pesavento (1994), já que é o olhar que qualifica e instrui uma semântica para o mundo social. As conquistas sociais, portanto, são objetos de disputas simbólicas nas quais os atores sociais constroem, por meio de uma história mais ampla em que é possível ressaltar as minorias e cuja diversidade criadora material e imaterial legitima, um patrimônio cultural que legitima uma identidade local que dialoga com os valores universais.

\section{HERITAGE AND CULTURAL PERFORMANCE: EXPERIENCE AND TERRITORIALITY IN THE CONQUEST OF SPACE}

Abstract: The present article has the objective of doing a teorical reflection exercise about the concepts of territory, cultural performance and immaterial patrimony in order to seek to emphasize the correlation between the ideas of memory, culture, identity and territoriality. It is understood here concept of performance in a broad perspective in which it refers to a meaning related to the event, the human desire to experience, that is, the presentification of human actions performed as a singular expression of identities in the territorialization of spaces through of the meanings attributed to cultural heritage by social groups. In this article we seek a theoretical methodological path in which the proposal is to show through relations between the categories of analysis that the processes of production of the expression of this patrimony are realized not as crystallized product, but as a concrete act of creation and recreation, of signification and resignification of the representations of the subjects in a field of disputes of memories, since the human action expresses production of meanings in the here and now that, expressed through performance, territorialize the spaces.

Keywords: Heritage. Performance. Identity. Memory. Territory.

\section{Notas}

${ }^{1}$ Segundo Pierre Nora, "[...] o lugar de memória supõe, para início de jogo, a justaposição de duas ordens de realidades: uma realidade tangível e apreensível, às vezes material, às vezes menos, inscrita no espaço, na linguagem, na tradição, e uma realidade puramente simbólica, portadora de uma história. A noção é feita para englobar ao mesmo tempo os objetos físicos e os simbólicos sobre a base

Anos 90, Porto Alegre, v. 25, n. 48, p. 151-180, dez. 2018 
de que possuam 'qualquer coisa' em comum. Esta qualquer coisa é que o faz ser o caso. É espontânea e faz mais ou menos sentido para todos. Ao historiador cabe analisar esta 'qualquer coisa', desmontar-lhe o mecanismo, estabelecer-lhe os estratos, distinguir-lhe as sedimentações e as correntes, isolar-lhe o núcleo duro, denunciar as falsas semelhanças [...]. A identificação não é indiferente a conter a exumação, mas não é o principal trabalho do historiador. O que importa para ele não é a identificação do lugar, mas o desdobramento de que este lugar é a memória. Considerar um monumento como um lugar de memória não é simplesmente fazer a sua história. Lugar de memória, portanto: toda unidade significativa, de ordem material ou ideal, que a vontade dos homens ou o trabalho do tempo converteu em elemento simbólico do patrimônio memorial de uma comunidade qualquer" (1992, p. 20).

\section{Referências}

ARANTES, Antônio (Org.). O espaço da diferença. Campinas, SP: Papirus, 2000. ARÉVOLO, Javier Marcos. La Tradición, el patrimonio y la identidade. Disponível em: <http://dipbadajoz.es/publicaciones/reex/rcex_3_2004/etudios_02_ rcex_3_2004.pdf>. Acesso em: 14 set. 2009.

BAUDRILlARD, Jean. A Troca Simbólica e a Morte. Lisboa: Edições 70, 1976.

BENJAMIN, Walter. O narrador. Considerações sobre a obra de Nikolai Leskov. In: Magia e técnica, arte e política: ensaios sobre literatura e história da cultura. 3. ed. São Paulo: Brasiliense, 1987. p. 197-221. (Obras Escolhidas, v. 1).

BOURDIEU, Pierre. A distinção: crítica social do julgamento. São Paulo: Edusp; Zouk, 2007.

CANDAU, Joël. Memória e identidade. Tradução Maria Leticia Ferreira. São Paulo: Contexto, 2016.

CASTORIADIS, Cornelius. A Instituição Imaginária da Sociedade. Tradução Guy Reynaud. Rio de Janeiro: Paz e Terra, 1982.

CERTEAU, Michel de. A invenção do cotidiano. Petrópolis: Vozes, 1994. v. 1. CHAGAS DE SOUSA, Mário. Museus, Literatura, Memória e coleção. In: LEMOS, Maria Teresa Torébio Brittes; MORAES, Nilon Alves (Org.). Memória e Construção de Identidades. Rio de Janeiro: 7 Letras, 2000.

Anos 90, Porto Alegre, v. 25, n. 48, p. 151-180, dez. 2018 
Patrimônio e Performance Cultural: Experiência e Territorialidade...

CHARTIER, Roger. A História Cultural entre práticas e representações. Tradução Maria Manuela Galhardo. Rio de Janeiro: Bertrand Brasil, 1990. (Coleção Memória e Sociedade).

CHOAY, Françoise. A alegoria do patrimônio. São Paulo: Unesp, 2001. p. 95-173. CRUCES, Francisco. Problemas en torno a la restitución del patrimonio. Una visión desde la antropología. Política y Sociedad, Madrid, n. 27, 1998.

DELEUZE, Gilles; GUATTARI, Félix. Mil Platôs. São Paulo: Ed. 34, 1997. v. 5.

FERREIRA, Maria Letícia Mazzuchi. Patrimônio: discutindo alguns conceitos. Diálogos, Maringá, PR, v. 10, n. 3, p. 79-88, 2006.

LONDRES, Maria Cecília. A construção do patrimônio: perspectiva histórica. In: . O Patrimônio em processo. 3. ed. Rio de Janeiro: UFRJ, 2009.

. Patrimônio e Performance: uma relação interessante. In: TEIXEIRA, João Gabriel; GARCIA, Marcus Vinicius; GUSMÃO, Rita. Patrimônio imaterial, performance cultural e (re)tradicionalização. Brasília, DF: TRANSE/CEAM, 2003.

GAGNEBIN, Jeanne Marie. História e narração em Walter Benjamin. 2. ed. São Paulo: Perspectiva, 1999.

GUMBRECHT, Hans Ulrich. Em 1926: vivendo no limite do tempo. São Paulo: Record, 1999.

HAESBAERT, Rogério. Concepções de território para entender a desterritorialização. In: SANTOS, Milton. Território, territórios: ensaios sobre o ordenamento territorial. 2. ed. Rio de Janeiro: DP\&A, 2006. p. 13.

EdUFF, 1997.

Des-territorialização e identidade: a rede "gaúcha” no Nordeste. Niterói:

. O Mito da Desterritorialização: do "Fim dos Territórios" à Multiterritorialidade. 2. ed. Rio de Janeiro: Bertrand Brasil, 2006.

HALL, Stuart. A identidade cultural na pós-modernidade. Tradução Tomaz Tadeu da Silva e Guacira Lopes Louro. 11. ed. Rio de Janeiro: DP\&A, 2006.

HOBSBAWN, Eric. A invenção das tradições. Rio de Janeiro: Vértice, 1990.

JELIN, Elizabeth. Los trabajos de la memoria. Madrid: Ed. Siglo XXI, 2002.

LONDRES, Cecília. Patrimônio e performance: uma relação interessante. In: TEIXEIRA, João Gabriel; GARCIA, Marcus Vinícius Carvalho; GUSMÃO, Rita (Org.). Patrimônio imaterial e performance cultural e (re)tradicionalização. Brasília, DF: Ed. UnB, 2004.

Anos 90, Porto Alegre, v. 25, n. 48, p. 151-180, dez. 2018 
NORA, Pierre. Entre memória e história: a problemática dos lugares. Projeto História, São Paulo, n. 10, p. 7-28, dez. 1993.

. Comment écrire l'historie de France? In: NORA, Pierre (Org.). Les France I. Paris: Gallimard, 1993. p. 11-32.

OLIVEIRA, Lúcia Lippi. Cultura é patrimônio. Rio de Janeiro: FGV, 2009. p. 139-159.

PADRÓS, Enrique. A história e a memória confiscada: o tempo presente e as ditaduras de segurança nacional. Clínicas do Testemunho: reparação psíquica e construção de memórias. Porto Alegre: Criação Humana, 2014. p. 195.

POLLAK, Michael. Memória, esquecimento, silêncio. Revista Estudos Históricos, Rio de Janeiro, v. 2, n. 3, 1989.

PESAVENTO, Sandra. História e História Cultural. Belo Horizonte: Autêntica, 2003.

- O Imaginário da Cidade: Visões Literárias do Urbano. Paris, Rio de Janeiro, Porto Alegre. Porto Alegre: Ed. UFRGS, 1999.

. História e imaginário urbano. Porto Alegre: UFRGS, 1994.

RICOEUR, Paul. A memória, a história, o esquecimento. Tradução Alain François et al. Campinas, SP: Editora da Unicamp, 2007.

SANTOS, Mariza Veloso Motta. Nasce a Academia SPHAN. Revista do Patrimônio Histórico e Artístico Nacional, Rio de Janeiro, n. 24, p. 77-95, 1996. Disponível em: <http://docvirt.com/docreader.net/DocReader.aspx?bib= $\backslash \backslash$ Acervo01 $\backslash$ drive_n $\backslash \operatorname{Trbs} \backslash$ RevIPHAN $\backslash$ RevIPHAN.docpro>. Acesso em: 20 abr. 2018.

SANTOS, Milton. A natureza do espaço. São Paulo: Editora da Universidade de São Paulo, 2006.

. O dinheiro e território. In: . Território, territórios: ensaios sobre o ordenamento territorial. Rio de Janeiro: DP\&A, 2006.

SCHECHNER, Richard. O que é Performance? O Percevejo: Revista de Teatro, Crítica e Estética, Rio de Janeiro, ano 11, n. 12, 2003.

SILVA, Rubens Alves da. Entre 'Artes' e 'Ciências': a Noção de Performance e Drama no campo das Ciências Sociais. Horizontes Antropológicos, Porto Alegre, v. 11, n. 24, jul./dez. 2005.

VELOSO, Marisa. Patrimônio imaterial, memória coletiva e espaço público. In: TEIXEIRA, João Gabriel; GARCIA, Marcus Vinícius Carvalho; GUSMÃO, Rita (Org.). Patrimônio imaterial, performance cultural e (re)tradicionalização. Brasília, DF: Ed. UnB, 2004. 
Patrimônio e Performance Cultural: Experiência e Territorialidade...

VELOSO, Sainy. Entre tablados e arenas: performances culturais. Urdimento: Revista de Estudos em Artes Cênicas, Florianópolis, v. 2, n. 23, 2014. Disponível em: 〈http://revistas.udesc.br/index.php/urdimento/article/ view/1414573102232014188>. Acesso em: 24 abr. 2018.

Recebido em: 25/04/2018 Aprovado em: 20/08/2018

Anos 90, Porto Alegre, v. 25, n. 48, p. 151-180, dez. 2018 